\title{
Improved diabetic control in a district general hospital clinic
}

\author{
J ALLGROVE
}

From the Department of Paediatrics, East Birmingham Hospital, Birmingham

SUMmaRY A clinic for diabetic children was established in 1983 in a district general hospital to coordinate the changeover to a standard 100 unit insulin regimen. The children's progress was monitored for the next three years. Glycated haemoglobin $A_{1}\left(H_{b A_{1 c}}\right)$, measured at the same time each year, fell from a mean (SD) of $15.8(4.7) \%$ to $9.9(2.6) \%$ over the three years. A similar degree of improvement was seen when newly diagnosed patients were excluded from the analysis. This improvement was associated with a rise in mean (SD) insulin dosage from 0.89 $(0 \cdot 29) \mathrm{U} / \mathrm{kg} /$ day to $1 \cdot 17(0 \cdot 35) \mathrm{U} / \mathrm{kg} /$ day. Good control was achieved more easily in children who had been diabetic for less than two years and in those who were prepubertal (particularly boys). A combination of isophane and soluble insulin appeared to be more effective than zinc and soluble insulin in maintaining good control. Ten complications of diabetes were noted in eight patients from $5 \cdot 2$ to $12 \cdot 4$ years after diagnosis.

These results show that setting up a diabetic clinic for children in a district general hospital had a beneficial effect on the quality of diabetic control and such improvement may help to reduce the incidence of diabetic complications.

During the past decade it has become accepted that improving the quality of diabetic control may delay the onset of complications as well as improving the wellbeing of patients without complications. In March 1983 insulins of a standard 100 unit strength (U100) were introduced in Great Britain partly to simplify insulin dosages and partly to avoid the confusion which had arisen from having two insulin strengths available (40 units and 80 units).

Changing patients from 40 unit and 80 unit regimens to U100 insulin in this department was undertaken by one person with a particular interest in diabetes. In setting up a clinic for diabetic children the opportunity was taken to examine the quality of control at the time of admission and to study any changes during the next three years.

\section{Patients and methods}

All diabetic children under the care of the consultants at East Birmingham and Solihull hospitals were admitted to the clinic. All patients remained nominally under the care of their original consultant who was kept informed of their progress. Newly diagnosed patients were also admitted to the clinic and followed up in the same way.
At each visit patients were measured using a Harpenden stadiometer and weighed. A sample of urine was taken and tested for the presence of protein, glucose, and ketones. At least once a year all patients had a full examination to exclude the presence of cataracts, retinal changes, hypertension, hepatomegaly, peripheral neuropathy and vascular disease. Pubertal development was assessed by the method of Tanner ${ }^{1}$ and with a Prader orchidometer. ${ }^{2}$ Puberty was considered to have occurred in girls if the menarche had been reached (mean age in normal children 13.0 years) and pubic hair of Tanner stage IV achieved (mean age in normal children 12.9 years), and in boys if they had pubic hair of Tanner stage IV (mean age in normal children 14.5 years) and testicular volumes of more than $12 \mathrm{ml}$ (mean age in normal children 14.4 years).

$C$ peptide concentrations were not measured. The prevalence of residual $\beta$ cell function, however, is almost $100 \%$ in patients who have had diabetes for less than two years ${ }^{34}$ but declines thereafter. Patients were therefore defined as 'established diabetics' if the diagnosis had been made more than two years previously and 'recently diagnosed' if it had been made within two years.

At most visits a blood sample was taken by 
venepuncture or finger prick for the measurement of glycated haemoglobin $\mathrm{A}_{1}\left(\mathrm{HbA}_{1 \mathrm{c}}\right)$, fructosamine (glycated serum proteins), and blood glucose concentrations. The term 'glycated' is used throughout in preference to the more familiar 'glycosylated' because of the non-enzymic nature of the reaction. $\mathrm{HbA}_{1 \mathrm{c}}$ was measured by a microcolumn technique with $\mathrm{m}$-phenyl-boronate agarose after incubation overnight to remove the unstable fraction. ${ }^{5}$ In this laboratory the assay has a coefficient of variation of $4 \%$ if $\mathrm{HbA}_{1 \mathrm{c}}$ is $12 \%$, and $8 \%$ if $\mathrm{HbA}_{1 \mathrm{c}}$ is $5 \%$. The method was not changed during the study. The laboratory is a founder member of the national quality control scheme for $\mathrm{HbA}_{1 \mathrm{c}}$ measurement of concentrations. This has shown no appreciable longitudinal alteration in results and the quality control performance has always been less than one SD of the mean for the method. ${ }^{6}$ The normal range for $\mathrm{HbA}_{1 \mathrm{c}}$ concentration is $5-9 \%$ (B Cockrill, personal communication), and $10 \%$ was the limit below which diabetic patients were considered well controlled. The results of the fructosamine estimations are being published separately.

To compare the efficacy of different insulin regimens 'soluble insulin' comprised Actrapid MC and Human Actrapid (Novo), Velosulin and Human Velosulin (Nordisk), and Humulin S (Lilly); 'isophane insulin' comprised Human Protaphane (Novo), Insulatard and Human Insulatard (Nordisk), and Humulin I (Lilly); and 'zinc insulin' comprised Monotard MC and Human Monotard (Novo), and Humulin $\mathrm{Zn}$ (Lilly). By the end of the three years most patients were controlled on human insulins manufactured by recombinant DNA methods.

All patients were taught to monitor blood glucose concentrations at home and given an Autolet (Ames) device with which to prick a finger to obtain a blood sample. Blood sugar was measured by either Visidex II (Ames) or B-M test 1-44 (Boehringer). Monitoring blood glucose concentrations at home was only introduced during the first year of the clinic; all but five patients accepted that it was the best way to monitor their day to day control.

Apart from one period of six weeks during the third year of the study patients were seen regularly by the author every three months and more frequently if problems arose. A dietitian was available to give advice but did not see all patients routinely. Two district nurses who had been trained by the home care team at Birmingham Children's Hospital were available to help manage patients at home, but in practice little expert nursing support or supervision outside the clinic was available. Most of the education of established diabetics was done in the clinic, and that of newly diagnosed patients in hospital. Following discharge from hospital the patients were seen frequently (weekly at first) until it was felt that they and their parents were able to cope for longer periods between visits. The author could be contacted by telephone most of the time and steps were taken to ensure that all patients had access to a telephone. Dietary advice was given according to current British Diabetic Association recommendations and total intakes of calories were adjusted to try and maintain an ideal body weight for height. Parents were instructed to alter their child's insulin dose in order to prevent appreciable hypoglycaemia or recurrent hyperglycaemia.

A record of type of insulin dosage, frequency of administration, and calculated dosage related to body weight was made and entered into flow sheets together with height, weight, and $\mathrm{HbA}_{1 \mathrm{c}}$ and blood glucose concentrations.

Assessment of obesity was made using the formula:

(actual body weight/actual body height) $\times(50$ th centile height for age/50th centile weight for age) $\times$ $100 .^{7}$

This formula overestimates obesity in tall children of appropriate weight but enables valid longitudinal assessment of obesity to be made. A value of greater than $120 \%$ indicated clinically important obesity. Three children who were also being treated for hypothyroidism were excluded from consideration of the effect of the increased dose of insulin on body weight.

$\mathrm{HbA}_{1 \mathrm{c}}$ measurements were made for all patients at their first visit to the clinic between April and June 1983. To avoid the effect of seasonal variations in $\mathrm{HbA}_{1 \mathrm{c}}$ concentrations, ${ }^{8}$ results of measurements made during the three months April to June were used for comparison each year. If more than one value was available from this period each year the nearest to the anniversary of admission to the clinic was used in the statistical calculations. It was only necessary to make a choice in $29(12 \%)$ instances. Other measurements were made at the same time.

The clinic population was studied in two groups. Most of the observations reported here refer to the results obtained from the entire group attending the clinic (group 1). Comparisons were also made between the following subgroups: male and female, prepubertal and postpubertal, established and recently diagnosed diabetics, those taking soluble and isophane insulins twice a day and those taking soluble and zinc insulins twice a day, and those whose $\mathrm{HbA}_{1 \mathrm{c}}$ concentrations were less than or greater than $10 \%$. To eliminate any spurious effect on improvement in control caused by the addition of new patients to the clinic, changes in $\mathrm{HbA}_{1 \mathrm{c}}$ concentrations were studied in a second group 
(group 2) which comprised only those patients who attended the clinic from its inception, were still attending three years later, and for whom four sets of data were available. The effect of increasing the dose of insulin on obesity was studied in these children at entry and after three years. Numerical values are expressed as mean (SD), and statistical comparisons were made by the Mann-Whitney U test, the Wilcoxon rank sum test, and the $\chi^{2}$ test with Yates' correction as appropriate.

\section{Results}

Table 1 gives details of patients in each subgroup of group 1 during each of the time periods studied together with their ages, insulin dosage, and $\mathrm{HbA}_{1 \mathrm{c}}$ concentrations. There were consistently about $20 \%$ more boys than girls in the clinic. Fifty two patients were admitted initially, and during the first year five new cases were diagnosed and one was transferred to the adult clinic. In the second year there were 16 new patients and two were transferred, and in the third year there were 10 patients and 10 were transferred. Thus for the last two years the clinic comprised 70 patients. Group 2 comprised 38 of these ( 21 boys and 17 girls). A total of 83 patients were seen in the clinic during the three years.

During the three years the mean age rose by one year from $12 \cdot 1(3 \cdot 0)$ years; and the proportion of postpubertal children increased from $13(25 \%)$ to 24
(34\%). The group included one girl with Down's syndrome who was 20 years old and still prepubertal, but she subsequently began menstruating; she has remained in the clinic.

The proportion of newly diagnosed patients rose from $5(9 \%)$ to $17(24 \%)$ and of those taking more than one injection a day from $17(33 \%)$ to $64(91 \%)$. Of the latter all but two were having two injections a day except two who were having four, three of Human Actrapid through a Novopen and one of Human Ultratard through a conventional insulin syringe. There was also a $31 \%$ increase in the mean insulin dosage from $0.89(0.29) \mathrm{U} / \mathrm{kg} /$ day in 1983 to $1.17(0.35) \mathrm{U} / \mathrm{kg} /$ day in $1986(\mathrm{p}<0.001)$.

Details of individual $\mathrm{HbA}_{1 \mathrm{c}}$ concentrations are shown in the figure. The mean initial $\mathrm{HbA}_{1 \mathrm{c}}$ concentration was $15.8(4.7) \%$ in the group as a whole and was higher in the girls than boys. Only one girl had a value of less than $10 \%$. During the next three years the mean $\mathrm{HbA}_{1 \mathrm{c}}$ concentration for the group fell significantly to $9.9(2.5) \%(p<0.0001)$ and was not significantly different between boys and girls, although over the three years the improvement occurred earlier in the girls than in the boys. By the end of the study $25(65 \%)$ of the boys and $16(52 \%)$ of the girls had concentrations of $\mathrm{HbA}_{1 \mathrm{c}}<10 \%$.

When the data on duration of diabetes were analysed $\mathrm{HbA}_{1 \mathrm{c}}$ concentrations did not seem to be higher in those patients with longstanding diabetes. This may have been because of the relatively small

Table 1 Details of patients in group 1

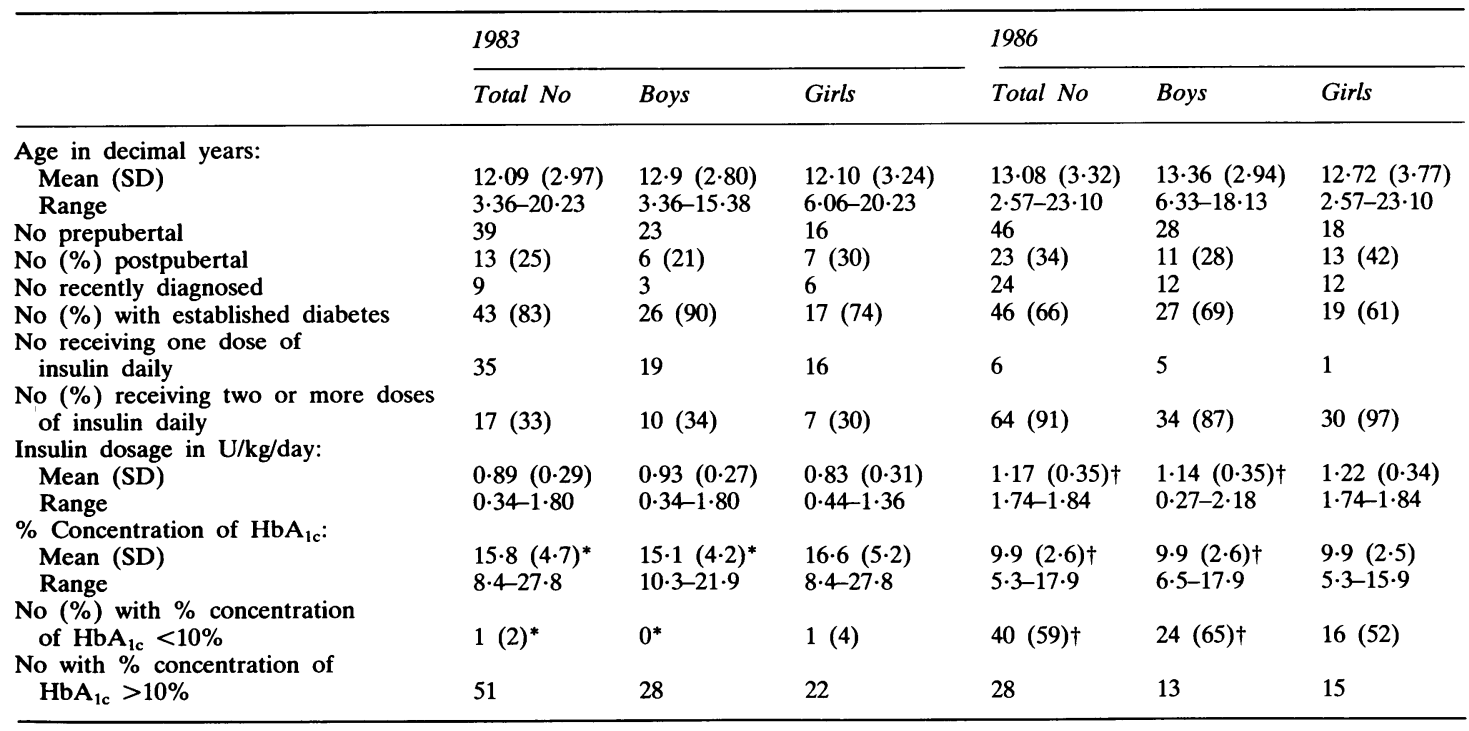

*One value not available; ttwo values not available. 

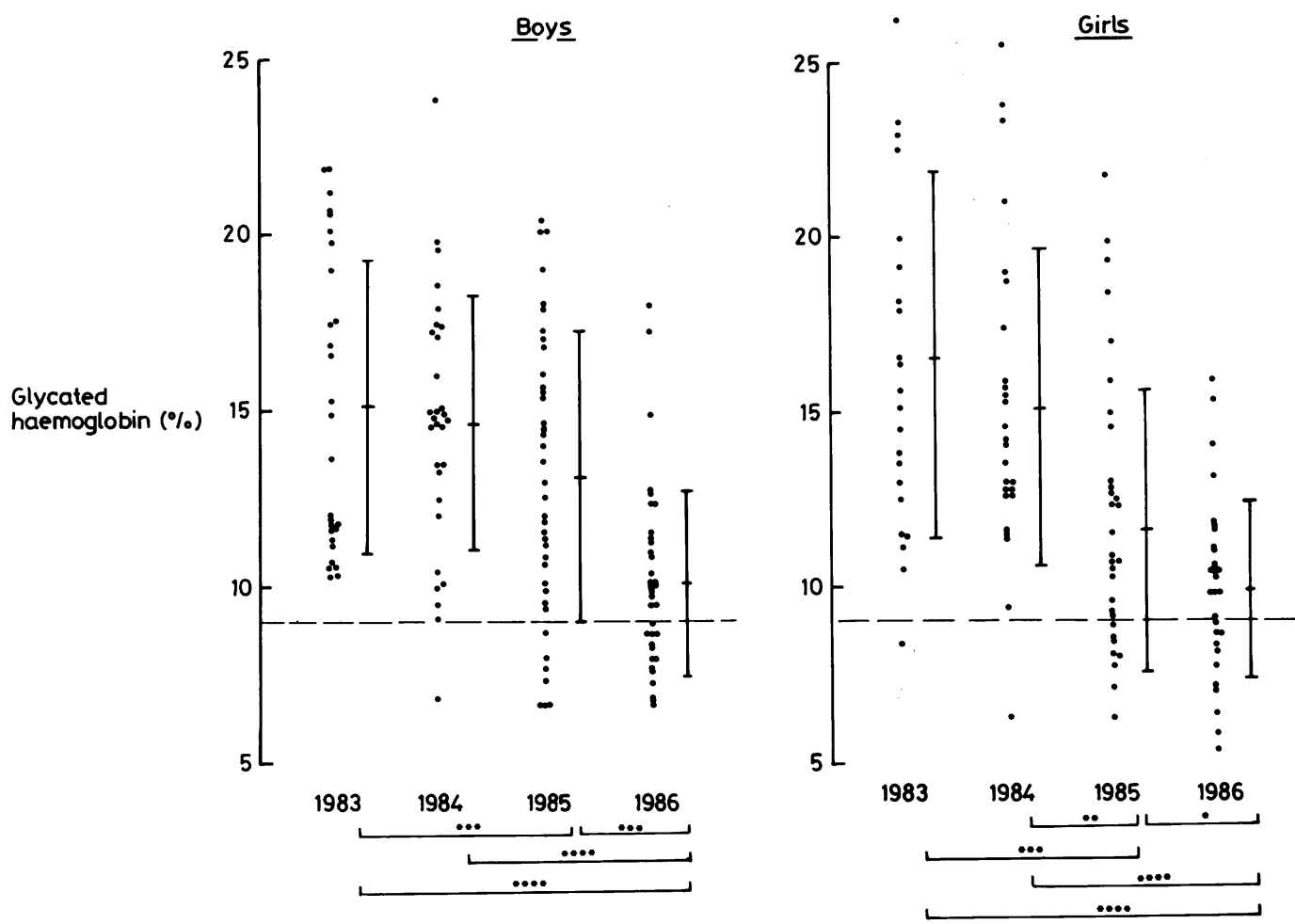

Figure Individual values of $\mathrm{Hb}_{\text {lc }}$ for boys and girls, 1983-1986. Each point is a single value from one patient taken between April and June. Vertical bars mean $(S D)$; interrupted line $=$ upper limit of $H b A_{I c}$ in normal subjects. ${ }^{*}=p<0 \cdot 05$; ${ }^{* *}=p<0.02 ;^{* * *}=p<0.0005 ;{ }^{* * * *}=p<0 \cdot 0001$.

numbers. Recently diagnosed children, however (those who had had diabetes for less than two years), were satisfactorily controlled $\left(\mathrm{HbA}_{1 \mathrm{c}}\right.$ concentration $<10 \%$ ) consistently more often than established diabetics; this difference was significant $(\mathrm{p}<0.001)$ in 1985.

Prepubertal children were easier to control than postpubertal children, and this difference was largely due to differences between prepubertal and postpubertal boys. Prepubertal boys had consistently lower $\mathrm{HbA}_{1 \mathrm{c}}$ concentrations despite being on lower doses of insulin, there being a significant difference in either or both in all four years. This was true irrespective of whether or not recently diagnosed patients were included.

When the association between the mean insulin dosage of those children taking a combination of soluble and isophane insulin was compared with that of those taking soluble and zinc insulin, data were included only if the children had been diabetic for at least two years and were taking insulin twice a day. At all four time periods the mean $\mathrm{HbA}_{1 \mathrm{c}}$ concentra- tions and the mean insulin doses were lower among those children taking soluble and isophane insulin than among those taking soluble and zinc insulin. There were significant differences between the two groups in mean $\mathrm{HbA}_{1 \mathrm{c}}$ concentrations in 1984 and 1986 and in mean insulin doses in 1983. When the results for the whole period were combined the difference between mean $\mathrm{HbA}_{1 \mathrm{c}}$ concentrations was highly significant $(p<0.001)$ and the difference in insulin doses was not significant.

Details of the 38 patients who remained in the clinic throughout the three years of the study (group 2 ) are shown in table 2 . The mean ages of the 21 boys and 17 girls were $11.6(2.0)$ and $11.1(3.1)$, respectively, and the mean duration of their diabetes $5.2(3.4)$ years and $3.4(2.9)$ years, respectively. None of the boys and only two of the girls were pubertal. By the end of the study eight boys and eight girls were pubertal. The mean $\mathbf{H b A}_{1 \mathrm{c}}$ concentration declined only slightly less than in group 1 during the three years. Within this group the index of obesity rose slightly from $100(15) \%$ to 
Table 2 Details of patients in group $2(n=38)$

\begin{tabular}{|c|c|c|c|c|c|c|}
\hline & \multicolumn{3}{|l|}{1983} & \multicolumn{3}{|l|}{1986} \\
\hline & Total No & Boys & Girls & Total No & Boys & Girls \\
\hline \multicolumn{7}{|c|}{$\%$ Concentration of $\mathrm{HbA}_{1 \mathrm{c}}$ : } \\
\hline Mean (SD) & $15 \cdot 0(4 \cdot 5)$ & $14 \cdot 3(3.9)$ & $15 \cdot 8(5 \cdot 2)$ & $10 \cdot 6(2 \cdot 7)$ & $10 \cdot 6(2 \cdot 9)$ & $10 \cdot 6(2 \cdot 4)$ \\
\hline Range & $8 \cdot 4-27 \cdot 8$ & $10 \cdot 3-21 \cdot 9$ & $8 \cdot 4-27 \cdot 8$ & $6 \cdot 4-17 \cdot 9$ & $7 \cdot 4-17 \cdot 9$ & $6.4-15.9$ \\
\hline \multicolumn{7}{|c|}{ Insulin dosage in $\mathrm{U} / \mathrm{kg} / \mathrm{day}$ : } \\
\hline Mean (SD) & $0.86(0.26)$ & $0.90(0.23)$ & $0 \cdot 81(0.29)$ & $1.28(0.29)$ & $1.29(0.29)$ & $1.30(0.31)$ \\
\hline Range & $0.34-1.30$ & $0 \cdot 34-1 \cdot 30$ & $0.44-1.19$ & $0 \cdot 74-2 \cdot 18$ & $0 \cdot 82-2 \cdot 18$ & $1 \cdot 74-1 \cdot 81$ \\
\hline
\end{tabular}

Table 3 Duration of complications

\begin{tabular}{lll}
\hline Complication & & $\begin{array}{l}\text { Duration of diabetes } \\
\text { (years) }\end{array}$ \\
\hline Retinopathy & $1(+? 1)$ & $5 \cdot 2$ \\
Nephropathy & 3 & $8 \cdot 0,8 \cdot 5,12 \cdot 4$ \\
Cataract & 3 & $8 \cdot 0,12 \cdot 4,6 \cdot 3$ \\
Necrobiosis lipoidica & 1 & 0 \\
Inflammation at & & - \\
$\quad$ site of injection & 2 & - \\
\hline
\end{tabular}

$105 \cdot 6(10 \cdot 6) \%$ in the girls, and from $97 \cdot 8(10 \cdot 3) \%$ to $99.1(12.4) \%$ in the boys. None of these differences was significant. The increase among the girls is mainly accounted for by the substantial increases in body weight of the three whose indices were less than $90 \%$ on admission to the clinic.

The diabetic complications are summarised in table 3. Ten complications occurred in eight patients. Two patients developed inflammation of the skin at the site of injection. One patient had necrobiosis lipoidica which had been present at the time of diagnosis, and three had cataracts, one of which required removal. Three patients had histological evidence of diabetic nephropathy, and two of these also had cataracts. One patient had early retinopathy. In addition one of the patients with diabetic nephropathy may also have had retinopathy, but this could not be confirmed on routine examination because of her cataract.

\section{Discussion}

East Birmingham Hospital is a large district general hospital serving an urban population of just over 200000 . About a quarter are less than 16 years old and about a quarter are from Pakistan and Bangladesh. It also serves diabetic children from the neighbouring district of Solihull which has a population of just under 200000 . Recent figures suggest that the prevalence of diabetes in children under 10 years old is about $1 \cdot 3: 1000.910 \mathrm{~A}$ population of 400000 , in which a quarter are under the age of 16 would therefore be expected to yield about 130 cases of diabetes and the size of the clinic is less than this. Nevertheless, it represents a fairly typical urban diabetic population.

Glycated haemoglobin has become established as the standard measurement of intermediate term control of diabetes and it reflects glycaemic control over the preceding four to six weeks. It is now clear, however, that there is a considerable seasonal variation in $\mathrm{HbA}_{1 \mathrm{c}}$ concentrations with a nadir in spring and early summer. ${ }^{8}$ It is therefore important to measure and compare $\mathrm{HbA}_{1 \mathrm{c}}$ concentrations taken at the same time each year to make valid comparisons from one year to the next. Because care was taken to do this the effect of seasonal variation was eliminated.

Concern about the need for good control has led to the establishment of special clinics for diabetic children during the past decade, and control has been improved. ${ }^{11}$ There is little information, however, about the results of establishing new clinics for diabetic children, or about the quality of control achieved by children not attending such clinics. The establishment of a children's diabetic clinic here has resulted in a considerable improvement in control as measured by the fall in mean $\mathrm{HbA}_{1 \mathrm{c}}$ concentrations.

Three aspects of the insulin dosages and regimens were associated with the improvement. Total mean insulin dosage increased and was accompanied by a substantial rise in the proportion of patients taking insulin twice a day and by a change to a combination of soluble and isophane insulin rather than soluble and zinc insulin. The mixture of soluble and isophane insulin seemed to be more effective in maintaining good control, and hypoglycaemia and obesity were not major problems. Furthermore, newly diagnosed and prepubertal children seemed to be easier to control than established or postpubertal diabetics. The former is likely to be due to persisting residual insulin secretion. The reasons for the latter observation, which is not new, ${ }^{11}$ can only be speculated upon but may help to explain part of the increase in insulin. The improvement in mean $\mathrm{HbA}_{1 \mathrm{c}}$ concentrations, however, cannot be attri- 
buted to the inclusion of newly diagnosed as well as established diabetics because the progress of patients in group 2 was nearly as good as that in the whole clinic.

It should be noted, however, that most of these observations were made retrospectively and the treatment groups were not adequately controlled to provide a sound basis for guidelines for insulin treatment. Nevertheless the observations are potentially valuable and may be confirmed by further work.

The introduction of the system of monitoring blood glucose concentrations at home may have been a factor in recognising the need to increase insulin dosages in some cases and it is worth noting that little improvement occurred during the first year before the system was introduced. Though it is a necessary part of assessing overall glycaemia and fluctuations in blood glucose ${ }^{12}$ monitoring blood glucose concentrations at home may only play a small part in maintaining control, and attention to other details is probably more important. ${ }^{13}$

Perhaps the most worrying aspect of this study is that ten complications occurred in eight of the 83 patients. The two instances of inflammation of the injection sites were probably caused by poor hygiene and they did not have any long term detrimental effects. The patient with necrobiosis lipoidica already had lesions at the time of diagnosis. There were, however, seven long term serious complications in five other patients. If it is accepted that improved control leads to a delay in the onset of serious complications, ${ }^{14-17}$ then it can only be concluded that the establishment of a paediatric diabetic clinic has led to a better prognosis for our patients.

Though the establishment of the clinic has led to an improvement in control and brought to light a few children with serious complications, it has also led to a number of benefits which are difficult to quantify and impossible to subject to statistical analysis. Many parents expressed their apprecïation of seeing the same person at each visit to the clinic and of receiving advice that was consistent from one visit to another. This is particularly important in the education of new diabetics in whom it is important to establish good habits and set high standards of control from the outset so that the risk of complications is reduced to a minimum.

This study has shown that a paediatric diabetic clinic in a district general hospital can confer considerable benefits. The results provide further evidence to support the recommendation of the British Paediatric Association that 'clinics for diabetic children be established in each district general hospital . . . There should be at least one paediatrician in each district with a special interest in diabetes' (British Paediatric Association Autumn Newsletter, 1986).

I thank Dr EE Hill, Dr ME Barton, Dr MJ Tarlow, Dr MH Winterborn, and Dr M Watkinson for agreeing to the establishment of a children's diabetic clinic, Dr PHW Rayner for helpful advice and for reading the manuscript, and Mrs P Jackson for typing the manuscript and preparing the figures. I also thank Mr B Cockrill for measuring the $\mathrm{HbA}_{\mathrm{lc}}$ concentrations.

\section{References}

1 Tanner JM. Growth at adolescence 2nd ed. Oxford: Blackwell Scientific Publications, 1962.

2 Zachmann M, Prader A, Kind HP, Hafliger H, Budliger $\mathrm{H}$. Testicular volume during adolescence. Helv Paediatr Acta 1974:29:61-72.

${ }^{3}$ Madsbad S, Faber OK, Binder C, McNair P, Christiansen C, Transbol I. Prevalence of residual $\beta$-cell function in insulindependent diabetics in relation to age at onset and duration of diabetes. Diabetes 1978;27(suppl 1):262-4.

${ }^{4}$ Marner B, Agner T, Binder C, et al. Increased reduction of fasting C-peptide is associated with islet cell antibodies in Type 1 (insulin dependent) diabetic patients. Diabetologia 1985;28: 875-80.

${ }^{5}$ Mallia AK, Hermanson GT, Krohn RI, Fujimoto EK, Smith PK. Preparation and use of a boronic acid affinity support for separation and quantitation of glycosylated hemoglobins. Analytical Letters 1981;14:649-661.

6 John WG. Glycated haemoglobin analysis-assessment of within and between laboratory performance in a large UK region. Ann Clin Biochem 1987;24:453-9.

7 Poskitt EME, Cole TJ. Do fat babies stay fat? $\mathrm{Br}$ Med $\mathrm{J}$ 1977;i:7-9.

${ }^{8}$ Hinde FR, Johnston DI. Two or three insulin injections in adolescence? Arch Dis Child 1986;61:118-23.

9 Jefferson IG, Smith MA, Baum JD. Insulin-dependent diabetes in under 5 year olds. Arch Dis Child 1985;60:1144-8.

10 Stewart-Brown S, Haslum M, Butler N. Evidence for increasing prevalence of diabetes mellitus in childhood. $\mathrm{Br}$ Med J 1983;286:1855-7.

11 Mann NP, Johnston DI. Improvement in diabetic control in diabetic adolescents by the use of increased insulin dose. Diabetes Care 1984;7:460-4.

12 Tattersall RB. Diabetes. I Measuring adequacy and lability of control. Arch Dis Child 1984;59:807-9.

13 Hocking MD, Rayner PHW, Nattrass M. Metabolic rhythms in adolescents with diabetes. Arch Dis Child 1986;61:124-9.

14 Pirart J. Diabète et complications dégénératives. Presentation d'une étude prospective portant sur 4400 cas observés entre 1947 et 1973 (première part). Diabete Metab 1977;3:97-107.

15 Pirart J. Diabète et complications dégénératives. Presentation d'une étude prospective portant sur 4400 cas observés entre 1947 et 1973 (deuxième part). Diabete Metab 1977;3:173-82.

${ }^{16}$ Pirart J. Diabète et complications dégénératives. Presentation d'une étude prospective portant sur 4400 case observés entre 1947 et 1973 (troisième part). Diabete Metab 1977;3:245-56.

17 Leslie ND, Sperling MA. Relation of metabolic control to complications in diabetes mellitus. $J$ Pediatr 1986;108:491-7.

Correspondence to $\mathrm{Dr} \mathrm{J}$ Allgrove, Department of Paediatrics, Dudley Road Hospital, Birmingham B18 7QH.

Received 30 July 1987 